\title{
A CONSTRUÇÃO E PERCEÇÃo DAS IMAGENS E MARCAS DO TURISMO CULTURAL. UM ESTUDO DE CASO DE TOLEDO (ESPANHA)
}

\author{
Luis Alfonso Escudero Gómez
}

\begin{abstract}
Resumo
As cidades hoje estão à venda. Elas são um produto comercial com uma marca e uma imagem. Os centros urbanos são destinos turísticos que competem entre si. Nesta matéria, ter uma imagem pública tão favorável quanto possível e ter uma marca de prestígio são questões essenciais para as cidades turísticas culturais. Elas atraem visitantes. Estes escolhem os seus lugares de viagem principalmente através da perceção que têm da imagem e da marca dos destinos. No entanto, essas representações do turismo cultural são estereótipos baseados numa seleção parcial e interessada da história e do património. Neste artigo, estudamos o processo de construção de imagens turísticas culturais num dos principais destinos da Península Ibérica, Toledo. Da mesma forma, analisa-se a perceção dos visitantes dessa imagem pública e a sua influência na escolha de destino. A metodologia utilizada, após uma revisão da literatura e uma compilação de informações sobre a imagem promocional de Toledo, baseia-se num trabalho empírico através de inquéritos. Descobrir-se-á que Toledo tem uma imagem estereotipada e uma marca baseadas numa visão parcial da sua história e no caráter pitoresco do seu património. É essa representação que atrai a grande maioria dos seus visitantes. Em contrapartida, a cidade real desaparece, tanto da imagem promocional de Toledo, como da perceção dos seus turistas e visitantes. Impõem-se o estereótipo e a comercialização da cidade como destino turístico cultural.
\end{abstract}

\section{PALAVRAS-ChAVE}

Geografia do turismo; imagem turística; marca de turismo; património; Toledo; turismo cultural

\section{THE CONSTRUCTION AND PERCEPTION OF CULTURAL TOURISM IMAGES AND BRANDS. A CASE STUdY FROM TOLEDO (SPAIN)}

\begin{abstract}
Cities are now up for sale. They are a commercial product, each with its own distinct brand and image. Urban centres have been transformed into tourism destinations that compete with each other. It is essential for cultural tourism cities to construct a prestigious brand and a public image that shows them in the best possible light. These are the elements that attract visitors. Tourists choose the places to visit mainly on the basis of their perception of each destination's image and brand. However, these representations of cultural tourism are ultimately stereotypical images, based on a partial and subjective selection of history and heritage. In this article, we study the process of construction of cultural tourism images in one of the Iberian Peninsula's main destinations - Toledo. The article also analyses visitors' perception of this public image and its influence when it comes to choosing a destination. The methodology used, after a literature review and compilation of information on Toledo's promotional image, is based on empirical analysis of surveys. The article demonstrates that Toledo has a stereotypical image and brand, based on a partial view of its history and the picturesque dimension of its heritage. It is this representation that attracts the vast majority of visitors to the city. On the other hand, the real city is disappearing, in terms of both the promotional image of Toledo, and in the perceptions
\end{abstract}


of tourists and visitors. The stereotypical image and commercialisation of the city as a cultural tourism destination is now the prevailing force.

\section{KEYWORDS}

Cultural tourism; geography of tourism; heritage; tourism brand; Toledo; tourist image

A imagem tem um efeito mais substantivo do que a realidade - é "hiperreal"

(Baudrillard, 1983)

A memória é redundante: repete os signos para que a cidade comece a existir (Calvino, 1998)

A imagem precede a cidade e medeia a relação que as pessoas têm com ela, tanto os viajantes como os cidadãos (Amendola, 2000, p. 167). As imagens modelam as identidades dos turistas, anfitriões, destinos e atrações turísticas. Uma imagem pode ser entendida como uma soma de crenças, ideias e impressões que uma pessoa tem de um destino (Crompton, 1979). Tem sido amplamente reconhecido o papel da imagem como um fator importante de motivação e de tomada de decisão em viagens de férias (Baloglu \& McCleary, 1999). As imagens representam um elemento fundamental no processo de decisão do turista (Beerli \& Martin, 2004). Por este motivo, as cidades realizam uma apresentação extremamente simplificada dos espaços que promovem com vista a atrair fluxos turísticos (Benach, 2016, p. 89).

A cultura tem sido promovida como atração turística por razões cada vez mais económicas, devido às receitas geradas nos destinos pelos turistas culturais. $\mathrm{O}$ turismo cultural, assim como outras modalidades de turismo, gera crescimento económico, investimento e emprego e, portanto, é uma atividade de grande mercado para gerar benefícios económicos para um destino (Gratton, 2005, p. 65). Isso levou à mercantilização da cultura, do património e do urbano. Benach (2016) fala sobre a venda da cidade no mercado turístico e de como se cria um sentido superficial do lugar. Román (2005, p. 47) aponta que o sistema de turismo espetacular transformou as cidades em caricaturas de si mesmas. Apenas o brilhante e monumental são mostrados, dando origem a uma cidade simulada. As áreas cinzentas são evitadas ou ocultadas, o que significa que elas não podem ser compreendidas. A História e o património cultural são fatores que determinam a imagem dos lugares (Jansen-Verbeke \& Lievois, 1999, p. 88). Dão origem a estereótipos que são usados pelos destinos turísticos culturais. Urry (1990) explicou o processo no qual o turista precisa de encontrar as visões estereotipadas que o turismo Ihe oferece. As imagens culturalizam o turismo e a experiência do mesmo e turistificam as culturas dos anfitriões.

Numerosos estudos analisaram as imagens de destinos turísticos como Estados, regiões e cidades (Beerli \& Martín, 2004; Gartner, 1989; Jenkins, 1999). Pike (2002) faz 
uma revisão profunda da literatura relativa a análises das imagens dos destinos turísticos; Gertner (2011) fá-lo sobre o marketing de lugares e Almeyda e George (2017) sobre a construção de marcas de destino. Estes trabalhos são um subcampo dentro da pesquisa geral sobre imagens nas Ciências Sociais (Echtner \& Ritchie, 1991, p. 4). O objetivo principal que conduz este artigo é o de estudar o turismo cultural através dos discursos e imagens produzidos a esse respeito. Em trabalhos anteriores, o autor analisou o papel e a relevância da imagem no turismo (Escudero, 2005) e o processo de criação de uma imagem pública promocional e mediática (Escudero, 2013). Nesta última investigação, refere-se, para o caso de Santiago de Compostela, a criação de um estereótipo, baseado em valores patrimoniais e culturais, o mais favorável possível e que ignora a maioria das funções e realidades da cidade. Em estudos anteriores, chega-se ao mesmo tipo de conclusões, sobre Valência, onde se descobre que é criada uma imagem pública parcial, seletiva, deformada e concentrada no centro da cidade em causa (Boira \& Crespo, 1989); sobre Girona, onde a imagem promocional é uma seleção premeditada e concreta do conjunto de imagens da cidade (Galí, 2005, p. 23); sobre Sevilha, onde se demonstra como se constrói a imagem da cidade a partir de seu conjunto histórico (López, 2003) e sobre Barcelona, onde a construção de um imaginário capaz de captar a atenção do visitante oculta a realidade social da maioria da população (Cócola Gant, 2011). Muñoz (2010, p. 50) fala sobre "paisagens reduzidas a apenas uma das camadas de informação que as configuram, as mais imediatas e superficiais: a imagem". González Bracco (2017, p. 745) afirma que a perceção proposta pela imagem turística é pitoresca, isto é, necessariamente fragmentária, enganosa e encenada.

Neste artigo, a questão principal é a seguinte: a imagem turística cultural, promocional e estereotipada, determina a decisão de escolha de destino dos visitantes? A partir daí, os objetivos concentram-se em refletir sobre a construção de imagens e marcas de destinos turísticos culturais e em analisar a sua perceção pelos turistas e a forma como esta influencia a motivação para a escolha dos locais de viagem.

Para realizar esta pesquisa de maneira empírica, foi necessário escolher uma área de estudo. A análise qualitativa de casos é uma abordagem de pesquisa que facilita a exploração de um fenómeno dentro de um contexto específico, usando uma variedade de fontes de dados (Baxter \& Jack, 2008). Este método permite responder às questões de investigação apresentadas (Piva, Cerruti, Prats \& Raj, 2017, p. 100). O caso escolhido é o de Toledo, cidade média de 83.741 habitantes em 2017 (Instituto Nacional de Estatística, 2108) e um importante destino turístico cultural da Península Ibérica. A estrutura do artigo responde à questão e aos objetivos da pesquisa. Após esta introdução, desenvolve-se um referencial teórico para uma melhor compreensão do processo de construção das imagens e marcas do turismo cultural e da sua importância. Em seguida, surgem os resultados da investigação com uma seção dedicada à imagem pública e promocional de Toledo e outra com a análise empírica da perceção dos seus visitantes. Por fim, dedica-se uma epígrafe à conclusão e uma última às referências bibliográficas.

Este artigo contribui para a literatura de turismo cultural focada na análise das imagens e marcas de destinos. 


\section{QUADRO TEÓRICO}

Boulding (1956) explicou, já em meados do século passado, a importância da imagem em qualquer tipo de comportamento, isto é, no conhecimento subjetivo do indivíduo sobre o mundo e sobre si mesmo. Na esfera do mercado, a imagem de um produto é fundamental no processo de compra. As perceções, mais do que a realidade, são o que motivam os consumidores a agir ou a não agir (Gallarza, Gil \& Calderón, 2002). Especificamente, as imagens determinam o processo de decisão no turismo dos destinos (Echtner \& Ritchie, 1991). Hoje, cada vez mais há lugares desenvolvidos para o turismo e a oferta está em constante expansão. Os turistas têm que escolher entre uma variedade crescente de destinos. Os vendedores enfrentam um mercado complexo, global e competitivo, no qual influenciar a decisão do consumidor é fundamental. Um destino pode ser favoravelmente diferenciado nessa competição se for posicionado positivamente na mente de potenciais turistas (Echtner \& Ritchie, 1991, p. 2). Uma das principais chaves para conseguir isso é apelar a uma perceção ou imagem favorável e distintiva do destino turístico (Calantone, Di Benetto, Hakam \& Bojanic, 1989). Assim, uma imagem positiva do destino proporciona uma importante vantagem competitiva (Baloglu \& McCleary, 1999). A imagem do destino influencia o comportamento do turista (Hunt, 1975). As melhores são as que se consideram e escolhem no processo de decisão da viagem (Woodside \& Lysonski, 1989). Elas desempenham um papel fundamental no turismo (Chon, 1990). São um fator-chave para o seu desenvolvimento (Hunt, 1975), uma vez que determinam a escolha dos destinos (Um \& Crompton, 1990). Por essa razão, foram consideradas importantes, já há décadas, por organismos como a Organização Mundial do Turismo (OMT, 1980).

A formação de uma imagem é o resultado de uma construção mental baseada em poucas impressões escolhidas entre múltiplas informações (Reynolds, 1965). No caso das imagens dos destinos turísticos, essas diversas referências provêm de diferentes fontes que incluem a promoção turística, os meios de comunicação de massa e a opinião de outros como parentes, amigos, agentes de viagens, etc. Um estudo da Comissão Europeia (2016) mostrou que, para os turistas europeus, uma fonte fundamental de informação para decidirem os seus destinos vinha dos média, tanto dos convencionais (jornais, revistas, rádio, televisão e guias de viagem), 33\% usavam-nos, como dos em rede (sítios corporativos e redes sociais), 63\%. Os viajantes europeus também reconheceram a importância das recomendações de amigos e familiares, com $51 \%$ a levá-las em conta. No entanto, as representações que podem ser recebidas nessa relação social direta com pessoas próximas são mediadas, por sua vez, pela imagem pública e promocional que esses aconselhadores de viagens perceberam anteriormente. Posteriormente, essa imagem pode ser modificada pela experiência adquirida pelo turista após a sua viagem (Echtner \& Ritchie, 1991, p. 3). No entanto, o visitante prefere a emoção de encontrar o que ele já espera ver, para gerar a sua própria experiência (Cócola Gant, 2011). A perceção da viagem turística e o comportamento do turista no lugar da visita são, assim, profundamente mediados pelo estereótipo que ele já partilha quando parte para o destino. 
Em resumo, existem três categorias de imagens percebidas: a perceção apriori (a construção mental que um indivíduo faz de um lugar sem ter uma conexão física com ele), a perceção in situ (a observação que o sujeito faz entre o que ele imaginou e a realidade) e uma perceção a posteriori (a imagem idealizada que tiramos dos lugares) (Galí \& Donaire, 2006, p. 124). Na primeira fase do processo de escolha de um novo destino turístico, as fontes indiretas são a base da informação. Assim, a imagem promocional e mediática determina a perceção do potencial turístico (Escudero, 2005). Por esta razão, a construção de imagens turísticas é realizada artificialmente usando os princípios e práticas derivadas do marketing (Asworth \& Goodall, 1980; Avraham \& Ketter, 2008), tanto para a sua formação inicial (Gartner, 1993), quanto para as suas possíveis modificações ou melhorias, mais tarde (Chon, 1991). Estamos perante um "marketing da cidade" (Elizagarate, 2003; Paddison, 1993). Os DMOs', organismos responsáveis pela promoção do turismo, são os principais artífices da construção de imagens turísticas utilizando técnicas de marketing e os responsáveis pela competitividade do destino (Blain, Levy \& Ritchie, 2005; Pike \& Page, 2014). Nestas instituições, a política deu lugar à comercialização de cidades (Cócola Gant, 2011).

A imagem construída pelos DMOs, através dos média e da promoção turística, cria um estereótipo, uma representação repetida e parcial do espaço real (Escudero, 2013). Cada indivíduo tem uma única imagem mental (Downs \& Stea, 1977) do destino, mas há também uma imagem mental pública comum desse destino ou estereótipo (Echtner \& Ritchie, 1991, p. 7). Nestas imagens públicas, os atributos variam em função dos destinos e das tipologias da atividade turística, mas procura-se sempre a representação mais favorável possível para persuadir o ou a visitante a viajar para o ponto turístico correspondente. Elas criam uma impressão holística composta de caraterísticas funcionais tangíveis e outras de natureza psicológica com aspetos mais intangíveis (Echtner $\&$ Ritchie, 1991, p. 8). No entanto, é essencial destacar um único aspeto funcional como principal componente da imagem de um destino (Pearce, 1988).

No caso do turismo cultural e dos locais que participam dessa modalidade, a cultura, a história e o património são a matéria-prima para obter essa excelente funcionalidade e tornar um estereótipo competitivo o suficiente para que as pessoas escolham o destino correspondente. No turismo, a história deve ser representada em imagens e, portanto, o prestígio histórico é concretizado em monumentos (Cócola Gant, 2011). O turismo cultural cria imagens patrimoniais fortemente estereotipadas, como se revela no estudo de caso de Santiago de Compostela (Escudero, 2013). A cultura é usada como instrumento para a espetacularização da imagem urbana (Fessler \& Berenstein, 2006). De fato, é necessariamente reduzida ao menor denominador comum (Fishman, 2004, p. 44). A cultura é utilizada como estratégia de consumo, produção e imagem (Fessler \& Berenstein, 2006). Nos destinos turísticos culturais, cria-se uma representação padrão de uma cidade histórica atraente, fortemente promovida pelos média (Jansen-Verbeke \& Lievois, 1999, p. 92). Constroem-se nestas urbes estereótipos da cidade da cultura (Evans, 2006). São as imagens do turismo cultural.

' DMO são as siglas do termo inglês Destination Marketing Organization (Sheehan, Vargas-Sánchez, Presenza \& Abbate, 2016) 
Além disso, atualmente, há uma globalização do património, com uma representação superficial da história (Walsh, 1991). É um passado idealizado e saudável, de forma universal. Há uma tendência comum para destacar partes do passado que enfatizam eventos positivos e pessoas e excluem elementos que são desagradáveis e socialmente inaceitáveis (Timothy \& Boyd, 2003, p. 244). Em geral, apenas o "passado nobre" é retratado às custas da história real (Hardy, 1988). Nem todos os aspetos de ontem podem ser documentados, interpretados e vendidos a consumidores de património (Timothy, 2011 , p. 127). A complexidade e a riqueza da história urbana são reduzidas a caraterísticas simples, reconhecíveis e vendáveis (Ashworth \& Tunbridge, 1990). A história é simplificada, estereotipada e lançada no mercado como um produto sugestivo e de fácil consumo (Cócola Gant, 2011).

Por outro lado, os destinos turísticos recorrem à construção de marcas seguindo as técnicas usuais de marketing na grande maioria dos produtos de consumo (Gnoth, 1998). É o que países, regiões e cidades fazem (Kotler, Heider \& Rein, 1993), com um alto grau de complexidade (Pike, 2005). Uma marca de destino é um nome, símbolo, logotipo, marcador denominativo ou gráfico que a identifique e diferencie. Além disso, transmite a promessa de uma experiência de viagem memorável que é exclusivamente associada à designação. Também consolida e reforça a recolha de memórias agradáveis da experiência do destino (Ritchie \& Ritchie, 1998). Entre os principais valores que uma marca de uma cidade pode ter está a cultura, como evidenciado por Cócola Gant (2011) para a cidade de Barcelona, ou González \& Martínez (2013) para Cuenca.

A imagem do destino é integrada à da marca e constitui uma perceção única e final (Qu, Kim \& Im, 2011). Há uma confusão entre marca e imagem (Tasci \& Kozak, 2016). Os turistas têm uma perceção ou imagem da marca na sua memória (Almeyda \& George, 2017, p. 11). A marca atua como uma ferramenta promocional usada por países, regiões e cidades (Zeybeck \& Gül, 2016, p. 26). Ela é relevante para a escolha do destino ao qual confere uma identidade específica (Tasci \& Kozak, 2006). Por esse motivo, os territórios desenvolvem estratégias de branding para melhorar a sua reputação (Morgan, Pritchard \& Pride, 2011), diferenciar-se no mercado (Blain et al., 2005; Moilenen \& Rainisto, 2009) e ser mais competitivo (Anholt, 2007). A marca do destino serve para criar uma imagem que influencia positivamente a escolha de viagens do consumidor (Blain et al., 2005, p. 337).

Dessa forma, os nomes das cidades tornam-se marcas e os logotipos representam-nas (Arnaud, 2016, p. 23). Os centros urbanos lutam por um rótulo e uma imagem que os distingam e possam satisfazer o turista (Evans, 2006). Estamos agora perante a construção da marca da cidade [city branding] que na realidade faz parte das estratégias de marketing da cidade [city marketing] para a criação de imagens urbanas (Patteeuw, 2002). Marketing e branding tornaram-se atividades não apenas comuns, mas essenciais para os centros urbanos (Kavaratzis \& Ashworth, 2005). O resultado é que algumas cidades se transformam em marcas em si mesmas, em objetos de aquisição para os quais se viaja, que oferecem experiências ou monumentos como ícones urbanos de consumo (Muñiz \& Cervantes, 2010, p. 142). O património torna-se, assim, uma marca e um emblema promocional do turismo cultural (Timothy, 2011, p. 275). 
De facto, a comercialização da nostalgia, da tradição (Alsayyad, 2001), do passado (Rowan \& Baram, 2004), do valor da antiguidade (Cócola Gant, 2011), da autenticidade (Lovell \& Bull, 2017; Waitt, 2000), da educação e do entretenimento, através do uso de recursos culturais e patrimoniais, tem sido usada para ativar o turismo como um estímulo para a economia urbana e um valor agregado à vida das cidades. Assim, transformam-se as cidades num produto (Ward, 1998), num lugar-mercadoria, em espaços de prazer e consumíveis (Díaz, 2016, p. 217). Cócola Gant (2011) afirma que os núcleos urbanos são uma mercadoria, tal como todas as coisas tangíveis ou não tangíveis. São cidades construídas para os seus visitantes (Esinger, 2000). Os recursos patrimoniais são transformados em produtos turísticos (Jansen-Verbeke \& Lievois, 1999, p. 82). A cultura é explorada por aqueles a que Zukin (1991) chama de novos produtores. Trata-se da atual comercialização espetacular das cidades (Fessler \& Berenstein, 2006). Nesse contexto, o património cultural é um capital porque pode fornecer um fluxo de produtos e gerar recursos benéficos (Throsby, 2011). Com os bens patrimoniais, o negócio é feito através das práticas de comercialização da indústria do turismo (Harvey, 2013, p. 140). A consequência é uma acentuada tematização dos centros históricos, postos à disposição do turismo de massas e renunciando à sua tradicional complexidade social e funcional (Troitiño Troitiño \& Troitiño Torralba, 2010, p. 103).

\section{Metodologia}

A presente investigação adota o tipo de estudo de caso único explicativo (Yin, 2003). A realização deste artigo baseia-se numa revisão da literatura científica sobre o assunto. Depois deste primeiro e importante passo, foram recolhidas múltiplas informações sobre a imagem promocional turística de Toledo, quer novamente com referências bibliográficas prévias, quer por meio da análise de conteúdos de folhetos promocionais turísticos. No entanto, foi o trabalho de analisar a perceção das imagens do destino, partilhadas pelos visitantes de Toledo, e de averiguar se estas influenciaram a sua decisão de escolha, o que exigiu uma metodologia mais empírica, onde se optou pela realização de uma sondagem.

O estudo da imagem dos destinos turísticos tem sido realizado com metodologias estruturadas e não estruturadas. No primeiro caso, a análise de conteúdo e várias técnicas de classificação e categorização são usadas para determinar as dimensões da imagem. Em contraste, as metodologias não estruturadas são mais propícias para medir os componentes holísticos da imagem do produto e também para capturar caraterísticas únicas (Echtner \& Ritchie, 1991, p. 9). Elas são um modo alternativo de medição usado na pesquisa de imagens. Usam descrições obtidas de uma forma livre para medir a imagem (Boivin, 1986). Para este artigo, decidiu-se realizar uma investigação empírica baseada em questionários com uma metodologia não estruturada. Usando essa abordagem, os atributos da imagem não são especificados e permite-se que os inquiridos relatem mais livremente as suas impressões. Para as questões de investigação e os objetivos traçados, considerou-se que este era o método mais adequado. 
Como Reilly (1990), usaram-se questões abertas para permitir que os entrevistados descrevessem as imagens usando as suas próprias palavras e obtivessem uma impressão holística das mesmas. Ao permitir ao inquirido respostas livres, não se condicionam as suas respostas e pode-se avaliar de forma mais objetiva se a sua imagem foi influenciada pelo estereótipo de Toledo. Com esta metodologia, consegue-se uma imagem mais global e também os seus componentes exclusivos. Isso não é possível com o uso de respostas condicionadas, associado a técnicas comuns, como o diferencial semântico ou a escala Likert (método que usam, por exemplo, Park \& Petrick, 2006). Trocou-se assim a preferência mais comum pelas metodologias estruturadas de investigadores que medem as imagens de destinos turísticos (Echtner \& Ritchie, 1991, p. 9) por um questionário aberto que melhor se adequava aos objetivos perseguidos neste estudo.

\begin{tabular}{ll}
\hline & \multicolumn{1}{c}{ VSISTANTES } \\
\hline Universo populacional & \pm 2.000 .000 \\
\hline Tamanho da amostra $(\mathrm{n})$ & 510 \\
\hline Nível de confiança & $95 \%$ \\
\hline Erro amostral (sendo $\mathrm{p}=\mathrm{q}=50 \%)$ & $\pm 4,31 \%$ \\
\hline Técnica & Questionário pessoal presencial \\
\hline Trabalho de campo & Novembro de 2014 e de 2017 \\
\hline Programa informático & Microsoft Excel 2016 \\
\hline
\end{tabular}

Tabela 1: Ficha técnica do estudo

A pesquisa foi realizada em duas fases com três anos de intervalo nos meses de novembro de 2014 e 2017 . A principal questão para esta investigação foi a de procurar identificar as razões que levaram o ou a inquirida a escolher Toledo como destino. Também se obtiveram dados pessoais básicos, idade, sexo, bem como o tempo de visita à cidade, com o objetivo de distinguir entre aqueles que passam a noite, os turistas, e aqueles que não passam, os excursionistas. Neste artigo, não usámos os resultados de outras perguntas realizadas no questionário. Aplicou-se um total de 510 questionários nas ruas do centro histórico, o local principal de visita na cidade dos turistas (Troitiño Vinuesa \& Troitiño Torralba, 2009), de forma aleatória e por meio de um questionário pessoal face a face. O estudo das respostas foi feito através de um cálculo de percentagens e de uma análise qualitativa dos conteúdos.

\section{Resultados}

\section{A imagem pública turística CUltural de Toledo}

Toledo é uma cidade com um centro histórico e paisagens culturais declaradas $\mathrm{Pa}$ trimónio Mundial pela Unesco em 1986. Estima-se que receba dois milhões de visitantes por ano (Troitiño, García \& Street, 2003). As suas principais atrações são os seus valores 
culturais, históricos e patrimoniais que a tornam um importante destino de turismo cultural na Península Ibérica (Escudero, no prelo) e, obviamente, o destino principal da região (Esteban Talaya et al., 2011). A imagem pública desta cidade foi construída com base nesses recursos patrimoniais. Os DMOs de Toledo fizeram esforços para consolidar uma imagem forte e positiva do destino. Isso tem sido feito, principalmente, pelo "Patronato Municipal de Turismo" ${ }^{2}$, com foco na promoção do turismo da cidade e no fortalecimento da marca Toledo. Esse trabalho está a ser realizado, por exemplo, através da sua presença nas principais feiras do setor do turismo, como a FITUR (Feira Internacional de Turismo) em Madrid ou o ITB (International Tourism Börse) em Berlim, ou através da manutenção do seu portal digital e redes sociais (Patronato Municipal de Turismo de 2018).

Em Toledo, criou-se um estereótipo com o fim de transformar a cidade num destino cultural único (ver Figura 1). É uma representação pública o mais favorável quanto possível, embora longe de outras realidades e funções urbanas que não estão relacionadas com o património e a cultura. As paisagens culturais, os monumentos, a história e a arte constituem os elementos da imagem promocional de Toledo. Ao mesmo tempo, cria-se uma marca com slogans como "Toledo, experiências com a história" ou "Toledo, património dos sentidos", com os mesmos princípios baseados nos valores culturais e patrimoniais do seu centro histórico. Uma imagem pública limitada e estereotipada, tal como acontece noutros destinos turísticos culturais ibéricos importantes, como é o caso de Santiago de Compostela (Escudero, 2013). Além disso, como acontece no caso da capital de Compostela, os visitantes da cidade de Toledo adquirem essa imagem pública do destino por meio da promoção e dos média (Sistema de Investigação Turística de Castilla-La Mancha, 2009).

Para a construção da sua imagem urbana, com um caráter promocional e turístico, Toledo fez uma seleção do seu património histórico e cultural. Deste forma, recorreu a uma exaltação de um passado glorioso e seletivamente evocado através do qual definiu a sua imagem definitiva e ideal para enfrentar um futuro (Martínez, 2007, p. 121). Assim, destaca-se o tema da tolerância e da coexistência medieval entre cristãos, judeus e muçulmanos (García Fitz, 2002) na cidade através de uma das principais marcas difundidas de Toledo, a de "cidade das três culturas". A identidade de Toledo com uma ideia de tolerância idílica e convivência harmoniosa na Idade Média através da marca "a cidade das três culturas" é repetida em artigos académicos (Rico, Parra \& Beltrán, 2018, p. 149), em revistas informativas, como a National Geographic (González Ferriz, 2012), em produtos de turismo cultural ${ }^{3}$, em blogues na rede (Toledo medieval, la ciudad de las tres culturas, 2012), em documentários e reportagens sobre Toledo (Canal Documentales,

\footnotetext{
${ }^{2}$ Uma entidade de direito público criada em 1990 pelo Ajuntamento de Toledo, com personalidade jurídica e património próprios, independentes das do município, que gere a organização e administração da atividade municipal no campo do turismo em regime de descentralização ainda que tal não implique desvinculação do Ajuntamento. Na verdade, o presidente do Patronato é o alcaide.

${ }^{3}$ Retirado de http://www.toledo3culturas.com/quienes-somos/
} 
2016) e mesmo na principal enciclopédia colaborativa da internet ${ }^{4}$. Relativamente ao passado da cidade, não deve pensar-se, no entanto, num tempo pacífico e livre de contradições. Por exemplo, a expulsão dos judeus e o estabelecimento da Inquisição, ou a Guerra de Comunidades e os problemas de coexistência que afetaram os convertidos e os seus descendentes, revelam no passado de Toledo uma história violenta e com sombras (Almarcha, Díez de Baldeón, Peris \& Sanchez, 2011, p. 9).

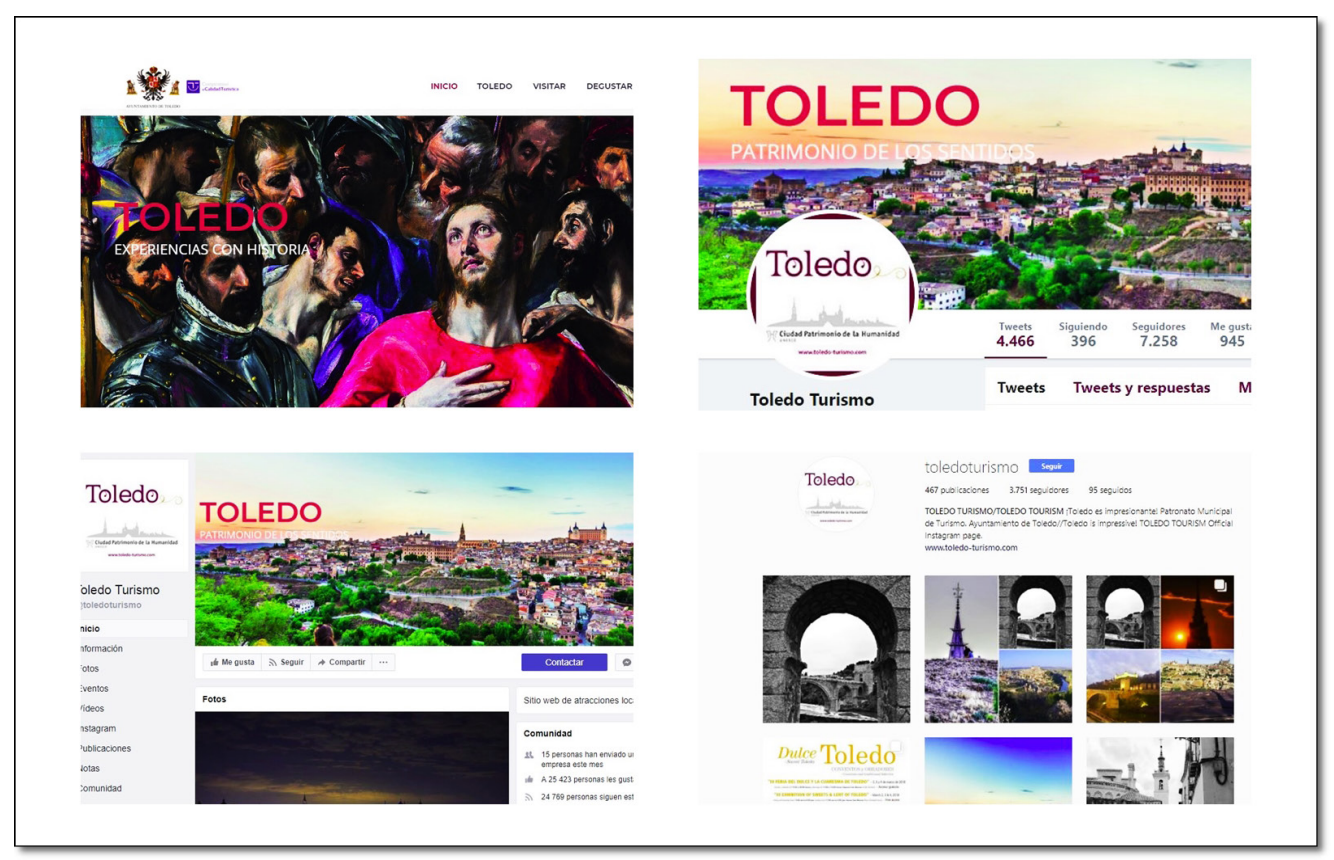

Figura 1: Promoção de Toledo na internet do Patronato Municipal de Turismo de Toledo: abrange o seu sítio na internet, Twitter, Facebook e Instagram

Fonte: https://turismo.toledo.es/

Esta imagem de Toledo baseada num passado idealizado que, por outro lado, contrasta com um presente de dormência, foi disseminada em todo o mundo por muitos autores que escreveram obras situadas em Toledo ou que fazem referência à cidade, desde o Romantismo ${ }^{5}$ até ao presente. Viajantes, escritores, fotógrafos, pintores, historiadores e jornalistas repetiram e divulgaram até à saciedade esta imagem (Almarcha et al., 2011, p. 322). Trata-se de uma representação assente numa visão idealizada do passado e numa cidade pitoresca (García Martínez, 2011). Exibe-se um Toledo como uma espécie de panóptico, museu ou arquivo da história e da arte de Espanha, uma ideia já claramente expressa por alguns escritores do século XIX (García Álvarez, 2007, p. 198). A partir deste século, Toledo foi um dos objetivos do viajante romântico e foco de um turismo incipiente que foi fomentado desde as primeiras décadas do século XX (Soto \& Perla, 2017). Enquanto em 1909 Toledo era visitado apenas por uns poucos milhares

\footnotetext{
4 Informação retirada de https://es.wikipedia.org/wiki/Toledo
}

${ }^{5} \mathrm{~A}$ literatura contribuiu em grande medida para criar as imagens do turismo cultural e as proporcionadas pelo Romantismo figuram entre as mais valiosas (Garcia Martinez, 2011, p. 437). 
de turistas, em 1913 esse número chegou aos 40 mil e o turismo tornou-se um fator importante na cidade (Storm, 2013, p. 351). Nessa época, figuras locais como o conselheiro conservador Manuel Cano Gutiérrez já prestavam atenção ao interesse económico que o turismo poderia ter e, para isso, insistiam que a cidade deveria enfatizar a herança judaica e árabe e usar o património para atrair visitantes (Storm, 2013, p. 373).

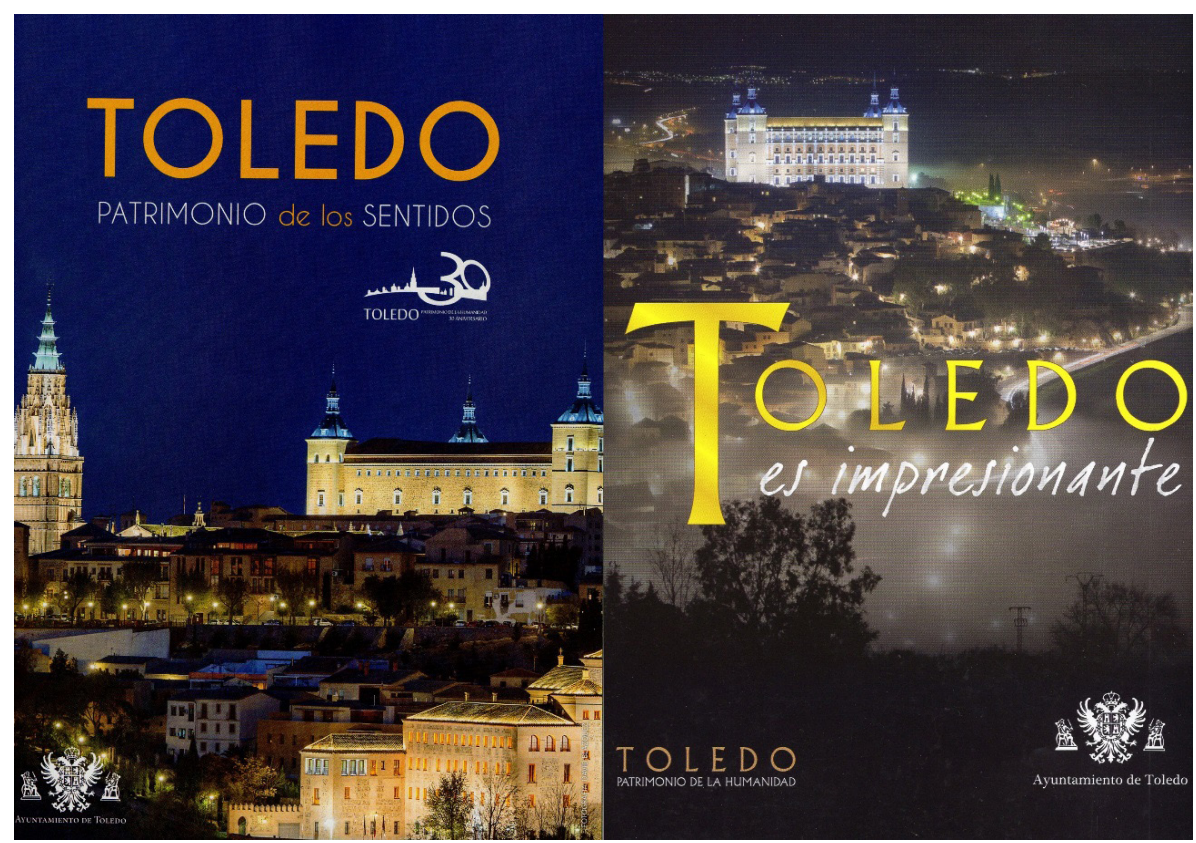

Figura 2: Imagens promocionais de Toledo

Fonte: Ayuntamiento de Toledo

Hoje, as imagens românticas de Toledo são usadas para o mercado turístico e, especialmente, para o segmento dedicado ao consumo de cultura (García Martínez, 2011, p. 451). Toledo tem atualmente uma imagem turística pública baseada em representações patrimoniais fragmentadas, selecionadas e idealizadas. Estas estão localizadas no seu centro histórico. Trata-se de uma imagem como destino turístico e patrimonial, onde se destacam os seus monumentos, as festas consideradas como produto turístico internacional (Semana Santa e Corpus Christi), as suas figuras artísticas e literárias mais importantes, as suas rotas patrimoniais e curiosidades sobre a sua história ou lendas (Rico, Parra \& Beltrán, 2018, p. 157). Este estereótipo, baseado num passado idealizado e selecionado e no seu legado patrimonial, traduz-se em paisagens formadas pela antiga cidade de Toledo e os seus monumentos. Estas são as fotografias que constituem repetidamente a imagem promocional da cidade (ver Figura 2).

Este estereótipo reforça-se pela criação de uma marca Toledo. Recorre-se assim, por exemplo, a diferentes apelos e slogans publicitários ${ }^{6}$ que acompanham as imagens

\footnotetext{
${ }^{6}$ Numa apoteose de criatividade, num só folheto promocional de Toledo encontramos os seguintes slogans que partilham o prefixo "in" em todos os adjetivos usados: "Toledo é... inesquecível", "Toledo é... inesgotável", "Toledo é ... imprescindível", "Toledo é ... incomparável", "Toledo é ... impecável”, "Toledo é ... imparável”, "Toledo é... inigualável”, "Toledo é ... infatigável", "Toledo é ... inconquistável”, "Toledo é... inimaginável" e "Toledo é... impressionante".
} 
patrimoniais e culturais. Apela-se a uma imagem afetiva do destino turístico que corresponde às emoções que Toledo irá gerar no turista, graças aos seus recursos culturais, históricos e patrimoniais.

É uma imagem pública de Toledo tão favorável quanto possível. Um estereótipo que determina não apenas a decisão dos visitantes, mas também o seu comportamento no destino e a sua avaliação final. Desta forma, numa nota de o a 10, os turistas e os excursionistas de Toledo dão um 8,4 à imagem global da cidade (SITdCLM, 2009).

No início da década atual, foi publicado um inquérito estruturado que mostrou ser a motivação cultural e patrimonial a que atraiu $92,4 \%$ dos seus turistas e excursionistas (SITdCLM, 2010). Este estudo já mostrou uma perceção dos visitantes baseada numa imagem do destino como uma cidade cultural e patrimonial. No entanto, ao lidar com respostas fechadas, não revelou quais os componentes únicos que formaram essa imagem. Deu-se ao entrevistado a escolha entre respostas estanques como "Cidade Património da Humanidade", "Catedral", "El Greco", etc. como motivação da sua viagem. Este fato influenciou muito as suas respostas face aos estereótipos previamente definidos pelos investigadores. Por esse motivo, realizou-se agora uma nova pesquisa com uma metodologia não estruturada.

\section{A PERCEÇÃo dos VisitANTES DA IMAGEM PROMOCIONAL DE TOLEDo E A SUA INFLUÊNCIA NA DECISÃO DE DESTINO}

Nos anos de 2014 e 2017, em novembro, foi realizado um inquérito presencial a 510 visitantes da cidade. Perguntou-se, de uma forma aberta, por que escolheram ir a Toledo. Os questionários foram realizados aleatoriamente na principal área turística da cidade, o centro histórico. Fizeram-se entrevistas a turistas $(n=275)$ e excursionistas ( $n$ $=235)$, de nacionalidade espanhola $(n=310)$ ou estrangeira $(n=190)$ e dos sexos masculino $(n=250)$ e feminino $(n=260)$.

Para a análise dos questionários realizados, procedeu-se a uma síntese das respostas, com muito variação por serem livres, criando uma série de itens principais indicados como causa para a visita a Toledo7 (ver Gráfico 1).

Oitenta e oito vírgula cinquenta e três por cento dos entrevistados vieram para Toledo atraídos pelo seu património. Depois deste grande motivo principal, e a muita distância, surge a visita a familiares e amigos $(5,88 \%)$, os estudos $(1,76 \%)$ e a gastronomia, os negócios e o lazer e entretenimento ( $1,18 \%$ em cada um dos três itens) como causas para a viagem a Toledo A primeira conclusão obtida é que a grande maioria dos visitantes da cidade responde à chamada da imagem do turismo cultural de um núcleo urbano patrimonial. Ou seja, são motivados pela marca Toledo.

Entre as pessoas que respondem que o património é a causa de sua visita, aparecem referidas nas suas respostas certas apreciações, ou razões secundárias. Assim,

\footnotetext{
${ }^{7}$ Em concreto, identificaram-se os motivos seguintes: aprendizagem de idiomas, gastronomia, negócios, lazer e entretenimento, património e visita a família e amigos. Ao mesmo tempo, entre os inquiridos que indicavam o património da cidade como sendo a causa da sua visita, foi possível identificar as seguintes motivações secundárias: proximidade, excursão, história, literatura, recomendação, religião e visita familiar.
} 
alguns acrescentam que Toledo é uma cidade histórica (10,3\%). Excecionalmente, um entrevistado indicou ter sido atraído pela religião judaica e outro pela literatura. Todos estes aspetos enquadram-se na imagem pública, promocional e turística de Toledo. Uma representação que em 9,3\% das respostas se reconhece chegar aos visitantes de uma forma indireta, através de uma recomendação para a visita. Uma percentagem mínima, de $1,66 \%$, combina uma visita familiar com uma atividade de turismo cultural, atraídos também pelo património da cidade.

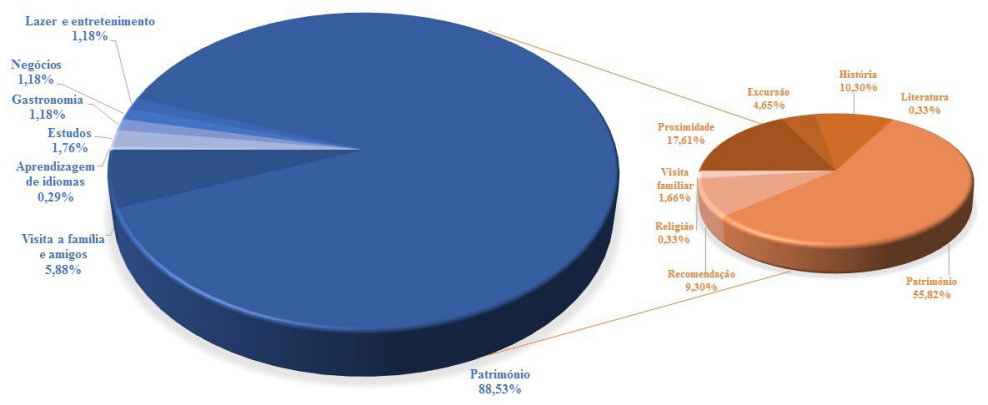

Grágico 1: Motivos de escolha do destino Toledo para os seus visitantes

Finalmente, é também digno de nota que alguns entrevistados $(17,6 \%)$ indicam de forma explícita como motivo para vir a Toledo a proximidade ao seu lugar de origem ou ao lugar de pernoita durante uma viagem de turismo e outros referem $(4,65 \%)$ que a sua visita se inclui numa excursão de roteiro fechado. Ambos os fenómenos estão relacionados, na maioria dos casos, com a proximidade da capital da Espanha, Madrid. Esta grande área metropolitana, destino turístico urbano principal na Península Ibérica, é a origem de um grande número de visitantes que chegam a Toledo por algumas horas e não passam a noite. É um fenómeno, o do excursionismo, que o autor estudou noutra investigação (Escudero, no prelo) e que agora aparece refletido de forma residual nos inquéritos deste estudo.

Analisando os dados obtidos nos questionários por perfis específicos dos visitantes da cidade, não obtivemos diferença significativa relativamente aos totais já apresentados (ver Tabela 2). Desta forma, e em primeiro lugar, tanto para os turistas $(84,15 \%)$, quanto para os excursionistas $(93,63 \%)$, o património é o principal motivo de sua visita. Como diferença, há um aumento de outras causas nos visitantes que passam a noite na cidade. Outra distinção, previsível, é que são os excursionistas que referem como causa da sua viagem a Toledo, numa percentagem muito maior $(31,97 \%)$, a proximidade de Toledo em relação ao seu local de origem ou de pernoita, Madrid fundamentalmente. 


\begin{tabular}{|c|c|c|c|c|c|c|c|}
\hline \multirow[b]{2}{*}{ Motivações } & \multirow{2}{*}{$\begin{array}{l}\text { TotaIs } \\
\begin{array}{l}\% \text { totais } \\
(n=510)\end{array}\end{array}$} & \multicolumn{2}{|c|}{$\begin{array}{l}\text { VISITANTES POR DU- } \\
\text { RAÇÃO DE ESTADIA }\end{array}$} & \multicolumn{2}{|c|}{$\begin{array}{l}\text { VISITANTES POR LU- } \\
\text { GAR DE ORIGEM }\end{array}$} & \multicolumn{2}{|c|}{ VISITANTES POR SEXO } \\
\hline & & $\begin{array}{l}\text { \% turistas } \\
(\mathrm{n}=\mathbf{2 7 5})\end{array}$ & $\begin{array}{l}\% \text { excursionistas } \\
(n=235)\end{array}$ & $\begin{array}{l}\% \text { nacionais } \\
(n=320)\end{array}$ & $\begin{array}{l}\text { \% estrangeiros } \\
(n=190)\end{array}$ & $\begin{array}{l}\text { \% homens } \\
(n=250)\end{array}$ & $\begin{array}{l}\text { \% mulheres } \\
(n=260)\end{array}$ \\
\hline $\begin{array}{l}\text { Aprendizagem } \\
\text { de idiomas }\end{array}$ & 0,26 & ০,০০ & 0,64 & ০,০০ & 0,79 & 0,60 & ০,০০ \\
\hline Estudos & 1,76 & 2,73 & 0,64 & 0,47 & 3,94 & 1,80 & 1,73 \\
\hline Gastronomía & 1,15 & 1,64 & 0,64 & 1,88 & 0,00 & 1,20 & 1,16 \\
\hline Negócios & 1,18 & 2,19 & ০,০০ & 1.41 & 0,79 & 2,40 & ০,০০ \\
\hline $\begin{array}{l}\text { Lazer e } \\
\text { entretenimento }\end{array}$ & 1,18 & 1,64 & 0,64 & 1.88 & 0,00 & 1,80 & 0,58 \\
\hline Património & 88,53 & 84,15 & 93,63 & 87,32 & 90,55 & 86,83 & 90,17 \\
\hline $\begin{array}{l}\text { Património- } \\
\text {-proximidade }\end{array}$ & 17,61 & 3,90 & 31,97 & 15,05 & 21,74 & 16,55 & 18,59 \\
\hline $\begin{array}{l}\text { Património- } \\
\text {-excursão }\end{array}$ & 4,65 & 3,90 & 5,44 & 4,84 & 4,35 & 2,76 & 6,41 \\
\hline $\begin{array}{l}\text { Património- } \\
\text {-historia }\end{array}$ & 10,30 & 12,34 & 8,16 & 7,53 & 14,78 & 10,34 & 10,26 \\
\hline $\begin{array}{l}\text { Património- } \\
\text {-literatura }\end{array}$ & 0,33 & ০,০০ & 0,68 & 0,54 & ০,০০ & ০,০০ & 0,64 \\
\hline $\begin{array}{l}\text { Património- } \\
\text {-recomendação }\end{array}$ & 9,30 & 10,39 & 8,16 & 7,53 & 12,17 & 11,03 & 7,69 \\
\hline $\begin{array}{l}\text { Património- } \\
\text {-religião }\end{array}$ & 0,33 & 0,65 & ০,০০ & ০,০০ & 0,87 & 0,69 & ০,০০ \\
\hline $\begin{array}{l}\text { Património- } \\
\text {-visita familiar }\end{array}$ & 1,66 & 3,25 & ০,০০ & 2,69 & ০,০০ & 2,07 & 1,28 \\
\hline $\begin{array}{l}\text { Visita família } \\
\text { e amigos }\end{array}$ & 5,88 & 7,65 & 3,82 & 7,04 & 3,94 & 5,39 & 6,36 \\
\hline
\end{tabular}

Em relação ao local de origem, é mais uma vez um Toledo patrimonial que motiva a viagem, tanto de visitantes nacionais (87,32\%), como internacionais (90,55\%). Nas pessoas que vieram do resto da Espanha, a visita à família e amigos aumenta a sua percentagem $(7,04 \%)$ em relação ao total. Nos visitantes estrangeiros também encontramos algumas pequenas diferenças: a proporção daqueles que indicam a proximidade como razão aumenta, novamente referindo-se sobretudo a uma excursão feita a partir de Madrid; a percentagem da viagem por estudos aumenta (3,94\%) e não há nenhuma resposta que aponte a gastronomia ou o lazer e entretenimento. Também é interessante que, entre as pessoas que vêm de outros países, a história tenha um peso maior como razão de escolha de Toledo (14,78\% das respostas relacionadas com o património sinalizam especificamente a história).

Finalmente, se levarmos em conta o sexo dos visitantes da cidade, o património é novamente o principal motivo de viagem, tanto para os homens $(86,83 \%)$, quanto para 
as mulheres $(90,17 \%)$. Como se pode verificar, a percentagem é maior entre os segundos. Entre outras razões, note-se que todos os entrevistados que responderam estar numa viagem de negócios eram homens. Entre as mulheres, a percentagem de visitas a familiares e amigos aumenta. Comparando as motivações mais específicas dentro da causa geral património, os homens apresentam uma proporção maior que a média em relação aos visitantes que vêm sob recomendação. As mulheres têm uma percentagem maior de respostas que referem vir a Toledo em excursão.

Após uma análise qualitativa sintética do conteúdo das respostas abertas dadas pelos entrevistados, fica clara de forma significativa a perceção da imagem da cidade. Destacam-se as referências à beleza de Toledo com adjetivos como bela ou, acima de tudo, bonita. Do mesmo modo, abundam as referências à importância da cidade e à sua fama. Por outro lado, o seu caráter cultural, monumental e patrimonial é repetidamente mencionado. Assim, o adjetivo histórico aparece com frequência nas respostas. Às vezes, fazem-se referências explícitas a marcos da cidade, como a catedral, ou a El Greco como uma figura histórica ligada a Toledo. Em resumo, cria-se a sinédoque entre Toledo histórico e Toledo, a parte pelo o todo, como também acontece noutras cidades médias com centros históricos, por exemplo em Girona (Galí, 2005).

Esta imagem de cidade histórica e patrimonial também se repete nas respostas abertas de pessoas que vêm a Toledo por recomendação. Assim, por exemplo, uma turista estrangeira de 32 anos respondeu que foi à capital Toledo "porque esta cidade está cheia de cultura e a minha prima recomendou-ma". Verifica-se na seguinte resposta de um excursionista estrangeiro de 43 anos: "eu estava em Madrid e queria passar um dia nesta cidade. É bonita, histórica. Tem cultura, religião”.

Troitiño Troitiño e Troitiño Torralba (2009, p. 239) apontam como uma das principais fragilidades da atividade turística de Toledo a persistência da sua imagem como destino cultural clássico. Sem dúvida, a sondagem mostrou que o estereótipo da cidade como local bonito, importante, histórico e com património é a imagem percebida pelos visitantes que chegam a Toledo. Essa perceção ajusta-se à representação promocional e turística da cidade. Há uma coincidência entre a imagem cultural construída e a percebida. Nesse sentido, os visitantes estão menos interessados em ver Toledo do que em visitar a Toledoland. Quer dizer, estamos perante uma visão fragmentada baseada em marcos históricos e patrimoniais selecionados e idealizados. É isso que o visitante procura. É também o que espera encontrar e o que encontra e recebe. Daí que depois recomendem esta mesma imagem a outras pessoas para que visitem este destino. Também por essa satisfação, encontramos na sondagem pessoas que retornam a Toledo por terem "gostado da cidade".

\section{Conclusão}

Neste artigo, colocou-se sobretudo a seguinte questão: a imagem promocional estereotipada do turismo cultural determina a decisão dos visitantes de escolha de destino? A resposta obtida na investigação empírica realizada em Toledo é totalmente 
afirmativa. No caso em estudo, construiu-se uma imagem e uma marca de turismo cultural baseadas no património do centro histórico de Toledo e na escolha de certos marcos históricos e personagens do passado para criar um estereótipo, o mais favorável possível, que atrai turistas. O Toledo cultural, histórico, patrimonial e pitoresco, o "impressionante Toledo", e a sua marca de "a cidade das três culturas" são o produto construído posto a circular no mercado, com o qual se comercializa a cidade. Esta imagem e marca turística cultural formam a representação pública de Toledo. Trata-se de uma visão, evidentemente, fragmentada e idealizada de natureza mercantil. Esta é a imagem percebida pelos visitantes da cidade. Por ela, vieram a Toledo.

Através da idealização e estereotipagem do património histórico e cultural de Toledo, produz-se uma desvirtualização do mesmo. No entanto, uma cidade é sempre uma realidade mais complexa do que um espaço para o turismo. Na imagem turística cultural da cidade, a realidade social de Toledo está escondida. De fato, a maior parte da superfície da cidade, onde quase todos os seus moradores vivem, desaparece, bem como as funções urbanas, exceto o turismo cultural.

Finalmente, de forma crítica e abrindo uma possível discussão, sugere-se aos construtores de marcas e imagens dos destinos turísticos uma maior responsabilidade para preservar a essência urbana e não apenas criar estereótipos idealizados para comercializar a cidade e atrair visitantes. É necessário situar o turismo nos seus próprios termos. É fundamental pensar em cidades com turismo e não em cidades turísticas. Caso contrário, muitos destinos turísticos culturais acabarão por se tornarem enclaves de monocultura turística, com exagerada turisficação funcional, se não o são já. Isso deixará a cidade em causa numa posição vulnerável, à mercê dos mercados e das tendências, à disposição de forças externas fora de controle.

\section{AgradeCimentos E FinANCiAmento}

O autor agradece aos seus alunos da unidade curricular "Turismo e Património" da Licenciatura em Humanidades e Património da Faculdade de Humanidades de Toledo pela sua colaboração na realização do inquérito. Também quer agradecer aos editores desta revista pelo seu trabalho. O artigo está incluído no projeto "Dinâmica da urbanização e políticas urbanas em cidades do interior. Da expansão e dispersão à reformulação: Para um urbanismo mais urbano? do Ministério da Economia e Competitividade / FEDER com a referência CSO2015-63970-R.

Tradução (castelhano-português): Zara Pinto-Coelho

\section{REFERÊNCIAS}

Almarcha Núñez-Herrador, E., Díez de Baldeón García, P., Peris Sánchez, D. \& Sánchez Sánchez, I. (2011). Paisajes de los conjuntos históricos: Castilla-La Mancha. Ciudad Real: Centro de Estudios de Castilla-La Mancha. 
Almeyda Ibáñez, J. A. \& George, B. P. (2017). The evolution of destination branding: A review of branding literature in tourism. Journal of Tourism, Heritage Q Services Marketing, 3(1), 9-17. DOI: 10.5281/ zenodo.401370

Alsayyad, N. (Ed.) (2001). Consuming tradition, manufacturing heritage. Global norms and urban forms in the age of tourism. Londres: Routledge.

Amendola, G. (2000). La ciudad postmoderna. Madrid: Celeste Ediciones.

Anholt, S. (2007). Competitive identity: the new brand management for nations, cities and regions. Basingstoke: Palgrave/Macmillan.

Arnaud, J. C. (2016), Logotypes and cities representations. In J. Calatrava \& F. García (Eds.), La cultura y la ciudad (pp. 23-32). Granada: Universidad de Granada.

Asworth, G. \& Goodall, B. (1980). Marketing in the tourism industry. Londres: Croom Helm.

Ashworth, G. J. \& Tunbridge, J. E. (1990). The tourist-historic city. Londres: Belhaven Press.

Avraham, E. \& Ketter, E. (2008). Media strategies for marketing places in crisis. Oxford: Butterworth-Heinemann.

Baloglu, S. \& McCleary, K. W. (1999). A model of destination image formation. Annals of Tourism Research, 26(4), 868-897. DOI: 10.1016/s0160-7383(99)00030-4

Baudrillard, J. (1983). Simulations. Nova lorque: Semiotexte.

Baxter, P. y Jack, S. (2008). Qualitative case study methodology: study design and implementation for novice researchers. The Qualitative Report, 13(4), 544-559.

Beerli Palacio, M. A. \& Martín Santana, J. D. (2004). Factors influencing destination image. Annals of Tourism Research, 31 (3), 657-681. DOI: 10.1016/j.annals.2004.01.010

Benach Rovira, N. (2016). ¿Ciudades en el mapa o en la guía turística? Venta de la ciudad y sentido de lugar. Revista CIDBO d'Afers Internacionals, 111, 89-105. DOI: 10.24241/rcai.2016.113.2.89

Blain, C.; Levy, S. E. \& Ritchie, J.R. B. (2005). Destination branding: insights and practices from destination management organizations. Journal of Travel Research, 43, 328-338. DOI: 10.1177/0047287505274646.

Boira Maiques, J. V. \& Crespo Berni, A. (1989). L'estudi d'un component de la formació de la imatge pública d'una ciutat: la prensa local diària. El cas de la ciutat de València. Cuadernos de Geografía, 46, 169-196.

Boivin, Y. (1986). A free response approach to the measurement of brand perceptions. International Journal of Research in Marketing, 3, 11-17. DOI: 10.1016/0167-8116(86)90039-x

Boulding, K. E. (1956). The image. Knowledge in life and society. Ann Arbor: University of Michigan Press.

Calantone, R. J., Di Benetto, C. A., Hakam, A. \& Bojanic, D. C. (1989). Multiple multinational tourism positioning using correspondence analysis. The Journal of Travel Research, 28(2), 25-32. DOI: $10.1177 / 004728758902800207$

Calvino, I. (1998). Las ciudades invisibles. Madrid: Siruela.

Canal Documentales (2016). Toledo, the city of the three cultures [vídeo do YouTube]. Retirado de https:// www.youtube.com/watch?v=EDJTmJ1RsyM

Chon, K. S. (1990). The role of destination image in tourism: A review and discussion. The Tourist Review, 2, 2-9. DOI: $10.1108 /$ ebo58040 
Chon, K. S. (1991). Tourism destination image modification process. Marketing implications. Tourism Management, 12(1), 68-72. DOI: 10.1016/0261-5177(91)90030-W

Cócola Gant, A. (2011). El Barrio Gótico de Barcelona. De símbolo nacional a parque temático. Scripta Nova. Revista Electrónica de Geografía y Ciencias Sociales, XV(371).

Comissão Europeia (2016). Preferences or Europeans towards tourism. Retirado de https://data.europa.eu/ euodp/es/data/dataset/S2065_432_ENG

Crompton, J. L. (1979). An assessment of the image of Mexico as a vacation destination and the influence of geographical location upon that image. Journal of Travel Research, 17(4), 18-23. DOI: $10.1177 / 004728757901700404$

Díaz Parra, I. (2016). Sevilla 1929-1992. La producción de una mercancía. In J. Rodríguez \& O. Salguero (Coords.), Cartografía de la ciudad capitalista. Transformación urbana y conflicto social en el Estado español (pp. 195-218). Madrid: Traficantes de Sueños.

Downs, R. M. \& Stea, D. (1977). Maps in minds. Reflections on cognitive mapping. Nova lorque: Harper \& Row.

Echtner, Ch. M. \& Ritchie, J.R. B. (1991). The meaning and measurement of destination image. The Journal of Tourism Studies, 2(2), 2-12.

Eisinger, P. (2000). The politics of bread and circuses. Building the city for the visitor class. Urban Affairs Review, 35(3), 316-333. DOI: 10.1177/10780870022184426

Elizagarate, V. (2003). Marketing de ciudades. Madrid: Pirámide.

Escudero Gómez, L. A. (2005). O valor da imaxe: un determinante para os destinos turísticos. In X.M. Santos (Ed.), Galicia en cartel: a imaxe de Galicia na cartelaría turística (pp. 63-78). Santiago de Compostela: Universidade de Santiago de Compostela.

Escudero Gómez, L. A. (2013). La imagen urbana de Santiago de Compostela (España), un estudio de su representación pública, mediática, promocional y artística. Boletín de la Asociación de Geógrafos Españoles, 62, 265-294.

Escudero Gómez, L. A. (no prelo). The realities and issues of a major cultural tourist destination in Spain, Toledo. Pasos, Revista de Turismo y Patrimonio Cultural.

Esteban Talaya, A., Lorenzo Romero, C., Andrés Martínez, M. E. \& Alarcón del Amo, M. C. (2011). ¿Conocemos a los visitantes de Castilla-La Mancha? Un análisis comparativo turistas vs. excursionistas. Pasos, Revista de Turismo y Patrimonio Cultural, 9(4), 531-542. DOI: 10.25145/pasos.2011.09.052

Evans, G. (2006). Branding the city of culture-The death of city planning?. In J. Monclús \& M. Guàrdia (Eds.), Culture, urbanism and planning [eBook]. Londres: Routledge.

Fessler Vaz, L. \& Berenstein Jacques, P. (2006). Contemporary urban spectacularisation. In J. Monclús \& M. Guàrdia (Eds.), Culture, urbanism and planning [eBook]. Londres: Routledge.

Fishman, R. (2004). Más allá del suburbio: el nacimiento del tecnoburbio. In A. Martín (Ed.), Lo Urbano en 20 autores C«contemporáneos (pp. 35-47). Barcelona: Universitat Politècnica de Catalunya.

Galí Espelt, N. (2005). La image turística del patrimoni monumental de Girona. Girona: Universitat de Girona.

Galí Espelt, N. \& Donaire Benito, J. A. (2006). La imagen percibida por los turistas de la ciudad de Girona. Revista Estudios Turísticos, 168, 123-139. 
Gallarza, M. G., Gil Saura, I. \& Calderón García, H. (2002). Destination image. Towards a conceptual framework. Annals of Tourism Research, 29(1), 56-78. DOI: 10.1016/s0160-7383(01)00031-7

García Álvarez, J. (2007). Paisajes nacionales, turismo y políticas de memoria: Toledo (1900-1950). Ería, 73-74, 193-212.

García Fitz, F. (2002). ¿La “España de las tres culturas"? El tópico de la tolerancia y los límites de la coexistencia en la España medieval. In M. J. Merinero (Ed.), Diálogo de civilizaciones Oriente-Occidente. Aporte al entendimiento internacional (pp. 127-155). Cáceres: Universidad de Extremadura.

García Martínez, C. (2011): La imagen en el turismo urbano: revisitando el Toledo romántico. Cuadernos de Turismo, 27, 437-453.

Gartner, W. C. (1989). Tourism image: attribute measurement of state tourism using multidimensional scaling techniques. Journal of Travel Research, 28(2), 16-20. DOI: 10.1177/004728758902800205

Gartner, W. C. (1993). Image formation process. Journal of Travel and Tourism Marketing, 2(3), 191-215. DOI: 10.1300/jo73VO2no2_12

Gertner, D. (2011). Unfolding and configuring two decades of research and publications on place marketing and place branding. Place Branding and Public Diplomacy, 7(2), 91-106. DOI: 10.1057/pb.2011.7

Gnoth, J.R. B. (1998). Branding tourism destinations. Annals of Tourism Research, 25, 758-759.

González Bracco, M. (2017). Guías, imágenes y suvenires: reflexiones sobre los artefactos mediadores de la práctica turística. Pasos. Revista de Turismo y Patrimonio Cultural, 15(3), 741-750. DOI: 10.25145/j. pasos.2017.15.049

González Férriz, R. (2012). Toledo, la ciudad de las Tres Culturas. National Geographic España. Retirado de http://www.nationalgeographic.com.es/viajes/grandes-reportajes/ toledo-la-ciudad-de-las-tres-culturas-2_6263/1

González Oñate, C. \& Martínez Bueno, S. (2013). La marca territorio como elemento de comunicación: factor estratégico del desarrollo turístico en Cuenca. Pensar la Publicidad, 7(1), 113-134. DOI: 10.5209/ rev_PEPU.2013.v7.nl.42439

Gratton, C. (2005). The economic context of cultural tourism. In G. Richards (Ed.), Cultural tourism in Europe (pp. 55-66). Association for Tourism and Leisure Education. Retirado de http://www.tram-research.com/ cultural_tourism_in_europe.pdf

Hardy, D. (1988). Historical geography and heritage studies. Area, 20, 333-338.

Harvey, D. (2013). Ciudades rebeldes. Del derecho de la ciudad a la revolución urbana. Madrid: Ediciones Akal.

Hunt, J. D. (1975). Image as a factor in tourism development. Journal of Travel Research, 13(3), 1-7. DOI: $10.1177 / 004728757501300301$

Instituto Nacional de Estadística (INE): Padrón municipal de 2017. Retirado de http://www.ine.es

Jansen-Verbeke, M. \& Lievois, E. (1999). Analysing heritage resources for urban tourism in European cities. In Pearce, D. G. \& Butler, R. W. (Eds.), Contemporary issues in tourism development (pp. 91-107). Nova lorque: Routledge.

Jenkins, O. H. (1999). Understanding and measuring tourist destination images. International Journal of Tourism Research, 1(1), 1-15. DOI: 10.1002/(sici)1522-1970(199901/02)1:1<1::aid-jtr143>3.0.c0;2-I 
Kavaratzis, M. \& Ashworth, G. J. (2005). City branding: an effective assertion of identity or a transitory marketing trick? Place Branding, 2(3), 183-194. DOI: 10.1057/palgrave.pb.5990056

Kotler, P., Heider, D. \& Rein, I. (1993). Marketing places: attracting investment, industry and tourism to cities, states and nations. Nova lorque: The Free Press.

López Lloret, J. (2003). La ciudad construida. Historia, estructura y percepción en el conjunto histórico de Sevilla. Sevilla: Diputación de Sevilla.

Lovell, J. \& Bull, C. (2017). Authentic and inauthentic places in tourism: from heritage site to theme parks. Abingdon: Routledge.

Martínez Gil, F. (2007). La invención de Toledo. Imágenes históricas de una identidad urbana. Ciudad Real: Almud.

Moilenen, T. \& Rainisto, S. (2009). How to brand nations', cities and destination: a planning book for place branding. Trowbridge: Cromwell Press Ltd.

Morgan, N., Pritchard, A. \& Pride, R. (2011). Destination brands: Managing place reputation. Londres: Routledge.

Muñiz Martínez, N. \& Cervantes Blanco, M. (2010). Marketing de ciudades y "place branding". Revista Pecunia: Revista de la Facultad de Ciencias Económicas y Empresariales, 1,123-149. DOI: 10.18002/pec. voimonogr.767

Muñoz, F. (2010). Urbanalización. Paisajes comunes, lugares globales. Barcelona: Gustavo Gili.

Paddison, R. (1993). City marketing. Image reconstruction and urban regeneration. Urban Studies, 30(2), 339350. DOI: $10.1080 / 00420989320080331$

Park, S. Y. \& Petrick, J. F. (2006). Destinations' perspectives of branding. Annals of Tourism Research, 33(1), 262-265. DOI: 10.1016/j.annals.2005.10.007

Patteeuw, V. (2002). City branding: image building and building images. Rotterdam: NAI Publishers.

Pearce, P. L. (1988). The Ulysses factor. Nova lorque: Springer Verlag.

Pike, S. (2002). Destination image analysis -a review of 142 papers from 1973 to 2000. Tourism Management, 23(5), 541-549. DOI: 10.1016/sO261-5177(02)00005-5

Pike, S. (2005). Tourism destination branding complexity. Journal of Product Q Brand Management, 14(4), 258259. DOI: $10.1108 / 10610420510609267$

Pike, S. \& Page, S. J. (2014). Destination marketing organizations and destination marketing: A narrative of the literature. Tourism Management, 41, 202-227. DOI: 10.1016/j.tourman.2013.09.009

Piva, E., Cerruti, S., Prats, L. \& Raj, R. (2017). Enhancing brand image through events and cultural festivals: The perspective of the Stresa Festival's visitors. Almatourism, 15, 99-116. DOI: 10.6092/ issn.2036-5195/6888

Qu, H., Kim, L. H. \& Im, H. H. (2011). A model of destination branding: integrating the concepts of branding and destination image. Tourism Management, 32(3), 465-476. DOI: 10.1016/j.tourman.2010.03.014

Reilly, M. D. (1990). Free elicitation of descriptive adjectives for tourism image assessment. Journal of Travel Research, 28(4), 21-26. DOI: 10.1177/004728759002800405 
Reynolds, W. H. (1965). The role of the consumer in image building. California Management Review, 7(3), 6976. DOI: $10.2307 / 41165634$

Rico Jerez, M., Parra Meroño, M. C. \& Beltrán Bueno, M. A. (2018). Las estrategias de marketing de las ciudades patrimonio como destinos turísticos: el caso de Toledo $30^{\circ}$ aniversario. International Journal of Scientific Management and Tourism, 4(1), 149-166.

Ritchie, J. R. B. \& Ritchie, R. J. B. (1998). The branding of tourism destinations: Past achievements and future challenges. In AIEST (Ed.), Proceedings of the 1998 Annual Congress of the International Association of Scientific Experts in Tourism Destination Marketing: Scopes and limitations (pp. 89-116). Marrakech: International Association of Scientific Experts in Tourism.

Román Alcalá, R. (2005). De la ciudad nómada a la ciudad ausente. In R. Román (Ed.), La ciudad: ausencia y presencia (pp. 31-48). Córdoba: Plurabelle.

Rowan, Y. \& Baram, U. (Eds.) (2004). Marketing heritage: archaeology and the consumption of the past. Walnut Creek: Altamira Press.

Sheehan, L., Vargas-Sánchez, A., Presenza, A. \& Abbate, T. (2016). The use of intelligence in tourism destination management: An emerging role for DMOs. International Journal of Tourism Research, 18(6), 549-557. DOI: $10.1002 /$ jtr.2072

Sistema de Investigación Turística de Castilla-La Mancha (SITdCLM) (2009). Imagen y marca turística de Castilla-La Mancha. Retirado de http://www.turismocastillalamancha.com/investigacion/.

Soto Caba, V. \& Perla de las Parras, A. (2017). Turismo y apropiación ideológica: la reconstrucción de Toledo como símbolo de las Reconquistas. In G. Belli, G. Capano \& M. I. Pascariello (Eds.), La città, il viaggio, il turismo. Percezione, produzione e trasformazione. CIRICE. Retirado de http://e-spacio.uned.es/fez/view/ bibliuned:409-Vsoto-5015

Storm, E. (2013). Patrimonio local, turismo e identidad nacional en una ciudad de provincias: Toledo a principios del siglo XX. Hispania, LXXIII(244), 349-376. DOI: 10.3989/Hispania.2013.010

Tasci, A. D. A. \& Kozak, M. (2006). Destination brands vs destination image: do we know what we mean?. Journal of Vacation Marketing, 12(4), 299-317. DOI: 10.1177/1356766706067603

Throsby, D. (2011). Cultural capital. In R. Towse (Ed.), A handbook of cultural economics (pp. 142-146). Cheltenham: Edward Elgar.

Timothy, D. J. (2011). Cultural heritage and tourism: an introduction. Bristol: Channel View Publications.

Timothy, D. J. \& Boyd, S. W. (2003). Heritage tourism. Harlow: Prentice Hall.

Toledo medieval, la ciudad de las tres culturas. (2012). Arquehistoria. Retirado de http://arquehistoria.com/ alfonso-x-y-la-integracion-de-las-tres-culturas-en-la-toledo-medieval-4157

Troitiño Vinuesa, M. A., García Hernández, M. \& Calle Vaquero, M. de la (2003). Los visitantes de las ciudades históricas españolas: caracteres generales y rasgos específicos inducidos por la celebración de eventos turísticos-culturales. In E. Ortega (Ed.), Investigación y estrategias turísticas (pp. 37-64). Madrid: ITES-Paraninfo.

Troitiño Vinuesa, M. A. \& Troitiño Torralba, L. (2009). Toledo: características y problemáticas de un destino patrimonial. In M. A. Troitiño (Ed.), Ciudades patrimonio de la Humanidad. Patrimonio, turismo y recuperación urbana (pp. 216-251). Sevilha: Universidad Internacional de Andalucía. 
Troitiño Vinuesa, M. A. \& Troitiño Torralba, L. (2010). Patrimonio y turismo: una complementariedad necesaria en un contexto de uso responsable del patrimonio y cualificación de la visita. Revista Patrimonio Cultural de España, 3, 89-108.

Um, S. \& Crompton, J. L. (1990). Attitude determinants in tourism destination choice. Annals of Tourism Research, 17(3), 432-448. DOI: 10.1016/0160-7383(90)90008-f

Urry, J. (1990). The tourist gaze. Leisure and travel in contemporary societies. Londres: Sage.

Waitt, G. (2000). Consuming heritage: perceived historical authenticity. Annals of Tourism Research, 27(4), 835862. DOI: $10.1016 /$ So160-7383(99)00115-2

Walsh, K. W. (1991). The representation of the past: museums and heritage in the postmodern world. Londres: Routledge.

Ward, S. (1998). Selling places. The marketing and promotion of towns and cities, 1850-2000. Londres: SPON.

Woodside, A. G. \& Lysonski, S. (1989). A general model of traveller destination choice. Journal of Travel Research, 17(4), 8-14. DOI: 10.1177/004728758902700402

World Tourism Organization (WTO) (1980). Tourist images. Madrid: WTO.

Yin, R.K. (2003). Case study research: design and methods. Thousand Oaks: Sage.

Zeybeck, B. \& Gül Unlü, D. (2016). A view on countries' tourism logos, slogans, contents and figural characteristics within the concept of country identity. Informacijos Mosklais, 76, 26-40. DOI: 10.15388/ Im.2016.76.10380

Zukin, Sharon (1991). Landscapes of power: from Detroit to Disney World. Berkeley: University of California Press.

\section{NOTA BIOGRÁFICA}

Luis Alfonso Escudero Gómez, nascido em Aarberg (Suiça) em 1971, de nacionalidade espanhola, é Doutor em Geografia pela Universidade de Santiago de Compostela desde o ano de 2000. É docente do Departamento de Geografia e Ordenamento do Território da Universidade de Castilla-La Mancha desde 2000, sendo Professor Titular de Geografia Humana desde 2007. Levou a cabo investigações sobre o turismo cultural e sobre a imagem urbana. Tem diversos artigos publicados em revistas como Treballs da Societat Catalana, Cuadernos Geográficos, Estudios Geográficos, The Open Urban Studies Journal e Boletín de la Asociación de Geógrafos Españoles.

Email: luisalfonso.escudero@uclm.es

Morada: Facultad de Humanidades de Toledo, Plaza de Padilla $n^{\circ}$ 4, 45071 Toledo, Espanha

* Submetido: 28-02-2018

* Aceite: 9-05-2018 